\title{
Speciation of Different Forms of Se in Bovine Blood by Enzymatic Extraction and HPLC/Photo-Reduction/HG-ICP-OES
}

\author{
Gian Paulo Giovanni Freschi ${ }^{a *}$ and Ana Rita Araújo Nogueira ${ }^{b}$ \\ ${ }^{a}$ Instituto de Ciência e Tecnologia, Universidade Federal de Alfenas, \\ 37715-400, Poços de Caldas-MG, Brazil \\ b Embrapa Pecuária Sudeste, P.O. Box 339, 13560-970 São Carlos, SP, Brazil
}

\begin{abstract}
Selenium is essential for the vital functions of the human and animal organism, such as growth, reproduction, prevention, and the protection of its muscular integrity. Although this dependence is well characterized, aspects related to selenium speciation still need to be studied further. This work describes the development of an alternative method for selenium speciation in bovine blood samples using a hyphenated analytical system (HPLC-UV-HG-ICP-OES). The influence of the main parameters related to the detection of $\mathrm{Se}$ species, such as separation efficiency, photo-reduction and hydride generation, were studied. Enzymatic reaction with proteinase- $\mathrm{K}\left(1\right.$ day at $\left.37^{\circ} \mathrm{C}\right)$ was employed for sample preparation. An on-line UV reduction system was adopted to convert the different species of Se to Se(IV).
\end{abstract}

For the chromatographic system, equipped with an anionic exchange column, a phosphatebuffer of $40 \mathrm{mmol} \mathrm{L}^{-1}$ in the $\mathrm{pH}$ of 6.0 was used as the mobile phase (flow rate of $1 \mathrm{~mL} \mathrm{~min}^{-1}$ ) for separation of the different Se species. To increase the sensitivity, hydride generation was used, followed by inductively coupled plasma optical emission spectrometry (ICP-OES) analysis. The developed method for Se speciation in bovine blood samples was performed completely on-line. The limits of detection (LODs) were 9.5, 7.2, 5.8, 3.1, 4.4 $\mu \mathrm{g} \mathrm{L^{-1 }}$ and the limits of quantification (LOQs) were 31.4, 23.9, $20.1,10.5$, and $14.5 \mu \mathrm{g} \mathrm{L}^{-1}$ for selenomethylselenocysteine, seleno-DL-methionine, Se(IV), and $\mathrm{Se}(\mathrm{VI})$, respectively. The recoveries obtained were $96 \%$ for Se(IV), 98\% for Se(VI), 91\% for selenocystamine, $89 \%$ for seleno-cysteine, and $84 \%$ for seleno-methionine.

\section{INTRODUCTION}

Selenium is an important element for humans and animals and is an essential nutrient at low concentrations but toxic at high levels. Deficiency is associated with several diseases such as cardiac and muscle injuries, Keshan disease, and causes damage to physiological conditions such as the reproductive system and other organs. Selenium is added to cattle diets in low quantities because the concentrations in forage and grains are very low.

\footnotetext{
*Corresponding autbor.

E-mail: gian.freschi@unifal-mg.edu.br

Tel: +553536974756
}

Cows supplemented with organic Se in the form of seleno-yeast during the placental stages and in milk transfer Se more effectively than cows given inorganic selenite (1). Thus, the determination of total selenium may not be a good tool to provide important information about essential Se concentrations, bioavailability, toxicology, nutrition, and other relevant aspects of this element $(2,3)$. The biochemical and physiological selenium effect is greatly dependent on total concentration and its chemical forms. Plants can absorb inorganic Se, such as Se(IV), and transform it into less toxic forms, i.e., seleno-amino acids as Se-methylselenocysteine
(MeSeCys) and selenomethionine (SeMet) (4-6).

About $75 \%$ of total Se in whole blood is present in the plasma/ serum, which suggests that this type of matrix can be a good indicator of the efficiency of dietary intake and supplementation (7-9). Studies of selenium speciation in blood samples are difficult due to the low Se concentrations present and the complexity of the matrix. Selenium in animal plasma is mainly present as selenoprotein-P (68\% \pm $7 \%)$, glutathione peroxidase $(25 \% \pm$ $4 \%)$, and is associated to albumin $(7 \% \pm 4 \%)$, which carries Se throughout the body $(10,11)$

Quantitative selenium speciation in biological matrices has been carried out by hyphenated techniques, such as chromatography (HPLC or GC) coupled to inductively coupled plasma mass spectrometry (ICPMS), most commonly used in combined systems (12-15). However, HPLC hyphenated to a spectrometric technique such as hydride generation atomic fluorescence spectrometry (HG-AFS), hydride generation atomic absorption spectrometry (HG-AAS), and hydride generation inductively coupled plasma optical emission spectrometry (HG-ICP-OES) can also be used for speciation. These kinds of detection systems are a good alternative due to low running costs, good linearity, and low detection limits (15-17).

Coupling ICP-OES with HPLC for on-line speciation can be achieved easily, since the flow rate of the HPLC pump and the uptake nebulizer rate are compatible in most cases. In practice, the outlet of the 
column is interfaced to the nebulizer of the ICP, or when an HG technique is used, the outlet of the column is interfaced to the HG system (16-18).

Although HG-ICP-OES proposes an improvement in sensitivity, such an advantage depends on the hydride generation efficiency. For instance, the quantitative reduction of Se(VI) to Se(IV) before hydride generation is the key point for improving the method. The efficiency of hydride generation depends on the chemical form of the analyte (its oxidation state and presence of a stable organometallic structure) which may delay or completely hinder the formation of the hydride, and is considered the "Achilles heel" of the technique. Consequently, a new step is necessary, the pre-reduction step. This procedure often requires some reagent such as KI (19), thiourea (20), $\mathrm{HBr}$ (21), and $\mathrm{HCl}$ (22) or more recently, a combination of alternative energies such as ultraviolet (23) and microwave (24). The $\mathrm{HCl}$ associated to $\mathrm{UV}$ is particularly attractive since a low acid concentration could be used for the prereduction step and in the carrier solution to hydride generation.

Sample preparation for speciation is not a trivial task and an alternative method should be employed. Many strategies have been adopted for speciation analysis such as solubilization, extraction, decomposition, and each could be appropriate depending on the objective of the analysis $(16,17,24)$.

The use of enzymes for extraction has been described in the literature (25-27). Recently, enzymatic extraction was performed using ultrasonic and microwave energy to improve analyte extraction and recoveries. The enzymes can catalyze specific and well-known steps. A study (28) of different enzymes reported the extraction of Se in mushroom with proteinase $\mathrm{K}$ and protease XIV by RP-HPIPC-ICPMS in which inorganic forms of Se, Se-cystine, Se-methionine, methylselenocysteine, and unknown Se forms were found. The method of using trypsin plus protease XIV (digestion III) for sample preparation was evaluated and found to give good results for speciation (28). However, sample preparation for speciation of selenium is still a major challenge since it is necessary to preserve the information of the analyte during analysis, especially for complex matrices.

The goal of this work was to develop a new and efficient method for Se speciation using hyphenated techniques in order to evaluate the effect of selenium in bovine blood for the purpose of monitoring nutrition supplements for cattle. The method using highperformance anion-exchange chromatography hyphenated to a photo-reduction step and hydride generation-inductively coupled plasma optical emission spectrometry (HPLC-UV-HG-ICP-OES) was evaluated. After UV radiation and hydride generation, different forms of Se were reduced and detected by radial ICP-OES. For sample preparation, an alternative enzymatic extraction method was used to preserve the species information. This method would be useful for a laboratory studying the selenium function and its mechanism in animal nutrition.

\section{EXPERIMENTAL}

\section{Solutions, Reagents, and Materials}

All solutions were prepared with high-purity chemicals and distilled deionized water (Milli-Q ${ }^{\circledR}$ system, Millipore Corporation, Bedford, MA, USA). Suprapur ${ }^{\circledR}$ hydrochloric acid (Merck, Darmstadt, Germany) was used to prepare the standard solutions. All solutions were stored in high-density polypropylene bottles (Nalgene ${ }^{\mathrm{TM}}$, Rochester, NY,
USA). The plastic bottles, flasks, and glassware were cleaned by soaking them in $10 \%(\mathrm{v} / \mathrm{v}) \mathrm{HNO}_{3}$. Before use, all materials were rinsed abundantly with deionized water.

Stocks solutions of Se(IV) were prepared from the dissolution of $0.1405 \mathrm{~g} \mathrm{SeO}_{2}$ (Aldrich, St. Louis, MO, USA) in $100 \mathrm{~mL}$ of $1 \mathrm{~mol} \mathrm{~L}^{-1}$ $\mathrm{HCl}$. The stock solutions of Se(VI) were prepared from the dissolution of $0.2393 \mathrm{~g}$ of $\mathrm{Na}_{2} \mathrm{SeO}_{4}$ (Aldrich, St. Louis, MO, USA) in $100 \mathrm{~mL}$ $0.1 \mathrm{~mol} \mathrm{~L}^{-1} \mathrm{HCl}$. Stock solutions of the Se organic forms (SigmaAldrich, St. Louis, MO, USA) were prepared by dissolving $0.071 \mathrm{~g}$ of $\mathrm{C}_{4} \mathrm{H}_{12} \mathrm{~N}_{2} \mathrm{Se}_{2}$ (dichlorhydrateselenocystamine), $0.101 \mathrm{~g}$ of $\mathrm{C}_{5} \mathrm{H}_{11} \mathrm{NO}_{2} \mathrm{Se}$ (seleno-DL-methionine), $0.099 \mathrm{~g}$ of $\mathrm{C}_{4} \mathrm{H}_{9} \mathrm{NO}_{2} \mathrm{Se}^{2}$ (chlorhydrateselenomethylselenocysteine), and $0.053 \mathrm{~g}$ of $\mathrm{C}_{6} \mathrm{H}_{12} \mathrm{~N}_{2} \mathrm{O}_{4} \mathrm{Se}_{2}$ (selenocysteine) in $50 \mathrm{~mL}$ of $0.2 \mathrm{~mol} \mathrm{~L}_{-1} \mathrm{HCl}$ with concentrations of $700 \mathrm{mg} \mathrm{L}^{-1}, 1000 \mathrm{mg} \mathrm{L}^{-1}$, $1000 \mathrm{mg} \mathrm{L}^{-1}, 500 \mathrm{mg} \mathrm{L}^{-1}$, and 5000 $\mathrm{mg} \mathrm{L}^{-1}$, respectively.

Sodium borohydride solution $(1.1 \% \mathrm{~m} / \mathrm{v})$ was prepared weekly by dissolving $0.5 \mathrm{~g} \mathrm{NaBH}_{4}$ (Merck, Darmstadt, Germany) in $100 \mathrm{~mL}$ of $0.5 \%(\mathrm{~m} / \mathrm{v}) \mathrm{NaOH}$ (Merck, Darmstadt, Germany). A 30\% $\mathrm{HCl}(\mathrm{v} / \mathrm{v})$ solution was used as the prereduced solution, prepared weekly, and stored in the refrigerator.

Solid reagents, such as sodium acetate, salicylic, and phosphate (Aldrich, St. Louis, MO, USA) were used as a buffer and employed as the mobile phase.

\section{Instrumentation}

A Varian Pro-star 210 high pressure chromatographic pump and a Varian Chromsep HPLC anionic exchange column (Varian, Mulgrave, Australia) were used for the separation technique. For enzymatic preparation of the sample, a Thermomixer 5436 heat-controlled system (Ependorff, Enfield, CT, USA) was employed. The outlet of the 
column was connected to a T-junction with concentrated hydrochloric acid solution, pushed by a Ismatec 8 peristaltic pump (Ismatec, Wertheim, Germany), which was employed in the photo-reduction step of the solutions and the samples when connected to ultraviolet energy. The connecting tubing was made of polyether ether ketone (PEEK). All mobile phases, standard solutions, and samples were filtered through $0.45 \mu \mathrm{m}$ membrane filters (Varian, Mulgrave, Australia). An AVISTAl RL ICP-OES with radial configuration (Varian, Mulgrave, Australia) was used as the detection technique, equipped with a concentric nebulizer. The optical system was purged with argon, and the wavelengths studied were from 167 to $785 \mathrm{~nm}$. A peristaltic pump was used in the photo-reduction system and a UV lamp (15 W) installed in a closed wood box was used to reduce the different species of Se organic and Se(VI) to $\mathrm{Se}(\mathrm{IV})$. The $\mathrm{pH}$ adjustments of the mobile phase and the buffer solutions were monitored using a conventional Metrohm $\mathrm{pH}$ meter Model 827 (Metrohm AG, Herisan, Switzerland). The instrumental and chemical operating conditions are listed in Table I.

\section{Sample Preparation}

The total and plasma bovine blood samples were collected in appropriate flasks containing heparin and stored for analysis in order to maintain the composition, chemical structure, and information for injection into the chromatograph after enzymatic hydrolysis. The reaction was accomplished in an incubation system maintaining a constant temperature of $37^{\circ} \mathrm{C}$ for 24 hours. For a 500-mL blood sample, $1.21 \mathrm{~g}$ of the enzyme was added, then incubated. The flasks containing the samples were centrifuged for 30 minutes under a rotation of $2500 \mathrm{rpm}$. For assessing the method prior to the speciation process, $0.5 \mathrm{mg} \mathrm{L}^{-1}$ of different forms of Se (sodium selenite and selenate, and dichlorhydrate selenocystamine, seleno-DL-methionine, chlorhydrate selenometylselenocysteine, selenocysteine) were added to the blood samples to evaluate the non-degradation of the organic species.

\section{Optimization of Hydride Gener- ation System in Interface}

All HG-ICP-OES parameters including the viewing plasma, RF power, nebulizer (argon gas), flow rate, sodium tetrahydroborate concentration and flow rate, hydrochloric acid flow rate used for $\mathrm{HG}$ were based on a previous work by our group (29). These parameters were initially tested and evaluated for Se speciation of $0.5 \mathrm{mg} \mathrm{L}^{-1}$ Se species. The integrated area emission intensity was calculated throughout the study and the ICP was operated in the continuous mode for $30 \mathrm{~min}$ utes.

\section{Procedure}

Speciation analysis was carried out by the proposed method for the separation and determination of the inorganic and organic seleno forms. The different species of Se were pre-reduced on-line to Se(IV), species more efficient to generate the hydride, then eluted from the chromatographic column. For the reduction step, two systems using ultraviolet energy were studied: (i) a photo-reduction system in a box consisting of a 15 W UV lamp; and (ii) a photo-reduction system using radiation by electrodeless discharge lamp (EDL) - UV/MW energy. The chromatographic column used in the separation stage was the ion-exchange column, and the system was evaluated using mobile phases appropriate for the column. For the mobile phases, buffer solutions of acetic acid, phosphoric acid, and salicylic acid were evaluated at different concentrations (20 to $100 \mathrm{mmol} \mathrm{L}^{-1}$ ) and at $\mathrm{pH}$ values ranging from 4 to 10 . The flow rates of each mobile phase were studied in the isocratic mode, and identification of the species was realized separately to determine the retention times of each species. The optimized instrumental operating parameters used

TABLE I

Optimum Parameters Used for HPLC-UV-HG-ICP-OES

\begin{tabular}{ll}
\hline RF power & $1400 \mathrm{~W}$ \\
Plasma view distance & $8 \mathrm{~mm}$ \\
Nebulizer flow & $0.9 \mathrm{~L} \cdot \mathrm{min}^{-1}$ \\
$\mathrm{NaBH}_{4}$ concentration & $1.2 \%(\mathrm{w} / \mathrm{v})$ \\
$\mathrm{NaBH}_{4}$ flow rate & $1.0 \mathrm{~mL} \mathrm{~min}^{-1}$ \\
Sample preparation & Enzymatic extraction \\
HCl flow rate & $0.1 \mathrm{~mL} \mathrm{~min}^{-1}$ \\
Selenium wavelength & $196.02 \mathrm{~nm}^{-}$ \\
HPLC & Pro-star 210 system operated \\
& at ambient temperature \\
Sample loop size & $100 \mu \mathrm{L}$ \\
Anion exchange column & ChromSep HPLC column \\
Mobile phase & $40 \mathrm{mmol} \mathrm{L}{ }^{-1}$ phosphate buffer at pH 6 \\
UV lamp & $15 \mathrm{~W}$ \\
\hline
\end{tabular}


for the HPLC-UV-HG-ICP-OES system are listed in Table $\mathrm{I}$, and a schematic diagram of the system is shown in Figure 1. Since no standard reference materials for speciation are available, the recovery studies were carried out in three replicates. The accuracy of the method was verified for the different Se species using addition and recuperation of $500 \mu \mathrm{g} \mathrm{L}^{-1} \mathrm{Se}$.

The proposed method was applied to the Se speciation in four bovine blood samples, and the efficiency of the method was evaluated with recovery tests using extracted blood spiked with $0.5 \mathrm{mg} \mathrm{L}^{-1}$ of selenocystamine, selenometylselenocysteine, seleno-DL-methionine, Se(IV), and Se(VI) from the samples. The limits of detection (LOD) and the limits of quantification (LOQ) were calculated according to IUPAC recommendations.

\section{RESULTS AND DISCUSSION}

\section{Sample Preparation}

The use of enzymatic hydrolyzation has shown good results for selenium speciation in a variety of samples and for different kinds of enzymes. It was found that time and temperature influenced the efficiency of the hydrolyzation process. The effectiveness of the bovine blood sample preparation was evaluated visually (color of the solution after the enzymatic reaction) and addition-recovery tests were performed for four species in the samples. The efficiency of the separation/pre-reduction/generation/analysis of the selenium standard added to the blood sample was evaluated by recovery tests of each selenium form. The solution was divided into two parts after the enzymatic reaction: the top was separated and injected into the speciation system. The enzymatic extraction provided a solution less viscous than the blood and a clearer solution. The recoveries were $96 \%$ for Se(IV), $98 \%$ for
Se(VI), 91\% for seleno-cystamine, $89 \%$ for seleno-cysteine, and $84 \%$ for seleno-methionine which proves the efficiency of the method.

\section{Optimization of Hydride Generation}

Selenium is an element that benefits with an increase in acidity during the hydride generation process and is affected by $\mathrm{HCl}$ concentration which is used as the carrier. The intensity of the emission for selenium broadened when the acid concentrations were increased from $10-20 \%$ to $30-50 \%(v / v)$. For subsequent studies, the concentration of $30 \%(\mathrm{v} / \mathrm{v})$ was used, resulting in better sensitivity and \%RSD for all selenium forms. The concentrations of $\mathrm{NaBH}_{4}(\mathrm{~m} / \mathrm{v})$ ranging from $0.4-1.5 \%$ were employed for the determination mono-elemental Se using flow injection analysis. Preliminary studies of the extracted sample showed a major formation of Se-hydride at $1.1 \%(\mathrm{~m} / \mathrm{v}) \mathrm{NaBH}_{4}$ and the same results were observed in the present study. Lower concentrations ( 0.4 to $1.0 \%)$ showed poor emission intensity, and concentrations higher than $1.2 \%(\mathrm{~m} / \mathrm{v})$ did not result in a significant emission improvement. Thus, the $\mathrm{NaBH}_{4}$ concentration used in this work was $1.1 \%(\mathrm{~m} / \mathrm{v})$ in $0.5 \%(\mathrm{~m} / \mathrm{v})$ $\mathrm{NaOH}$

\section{Optimization of Photo Reduc- tion System}

The parameters studied for the optimization of the pre-reduction step included $\mathrm{HCl}$ concentration, the ultraviolet system, and exposure time. The selected response for this study was the signal-tonoise ratio for all analytes. Since the organic Se species are more difficult to reduce to Se(IV), this characteristic was key to optimizing the system. The photo-oxidation/ reduction system using ultraviolet (UV) energy showed more quantitative pre-reduction of the different selenium species. Some factors influencing the efficiency of the photo-reduction process include exposure time of the species to UVradiation and the potency of the lamp. This first step studied was the off-line mode with UV-microwave assistance (EDL). This system showed an improvement in the efficiency process and only 2 minutes were necessary for the quantitative reduction of all forms. All organic species and Se(VI) were quantitatively reduced to Se(IV). However, when the on-line system was studied, problems of repeatability and reproducibility were observed, probably due to an excessive amount of gas formed. The other problem observed with the UV/MW system was the fast heating of the water by microwave, generating bubbles in the system, which

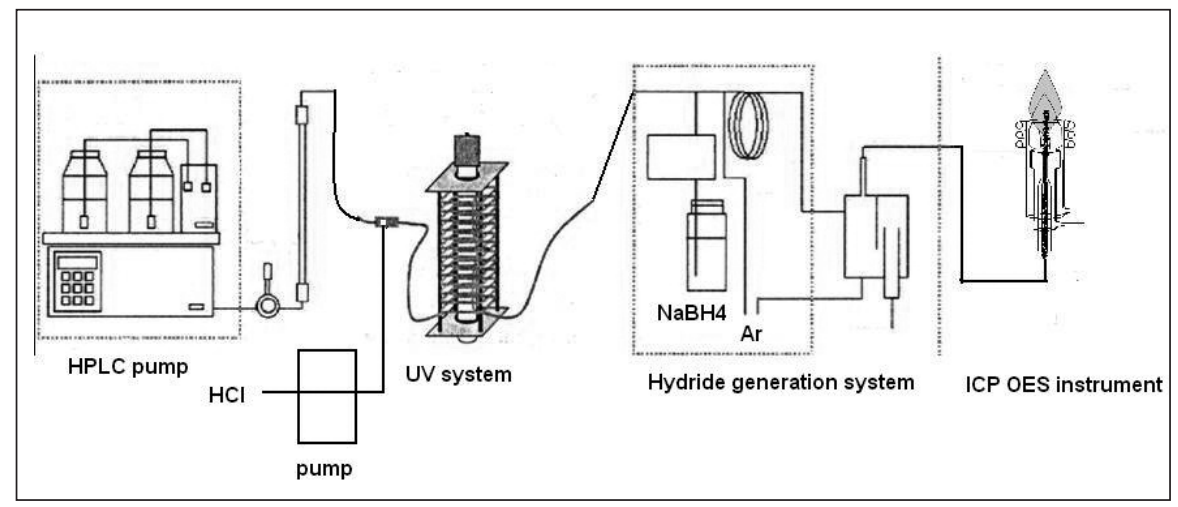

Fig. 1. Schematic diagram of the HPLC-UV-HG-ICP-OES hyphenated system. 
induced turbulence in the line, damaging the repeatability. This system was abandoned and the UVbox system was employed for the remaining work.

The exposure time of UV energy was studied by increasing the length of the coil resulting in a decrease in UV lamp energy. The flow of the solution and/or sample was determined by the exit flow from the chromatographic column $\left(1 \mathrm{~mL} \mathrm{~min}{ }^{-1}\right)$. It was found that an exposure time below 4 minutes did not provide an efficient reduction of the seleno-methionine species and Se (VI), but it was efficient for the seleno-cysteine and seleno-cystamine species. Within a time of 4 and 5 minutes, Se-methionine was reduced to the Se(IV) satisfactorily; but for Se(VI) no reduction was observed. However, all of the Se species were reduced after 6 minutes of exposure.

The use of the reagents (hydrobromic and hydrochloric acid) and the reducing agents $(\mathrm{KBr}, \mathrm{KI}$, and $\mathrm{K}_{2} \mathrm{~S}_{2} \mathrm{O}_{8}$ ) was also studied. The employment of hydrobromic acid was abandoned due to the poor reproducibility and low emission intensity for Se. The reduction with $\mathrm{KI}$ and $\mathrm{K}_{2} \mathrm{~S}_{2} \mathrm{O}_{8}$ was not satisfactory, possibly because there was no quantitative reduction to Se(VI) and/or a considerable interference from these agents. However, when just $\mathrm{HCl}$ associated to the UV light as employed in the photoreduction on-line system, the efficiency of pre-reduction of the different Se species was quantitative. Concentrations lower than $30 \%(\mathrm{v} / \mathrm{v})$ did not provide an efficient reduction of the different species. Best results were observed with a $30 \%$ (v/v) $\mathrm{HCl}$ concentration or higher and this condition was selected to study the pre-reduction step (Figure 2). Since the on-line system needs a (1:1) dilution at the confluence point between the reducing agent and the sample (Figure 1) after chromatographic separation, a $60 \%$ (v/v) volume of $\mathrm{HCl}$ was used with success. The mixture of $\mathrm{HCl}+\mathrm{KBr}$ provided an efficient pre-reduction of the different Se species, very similar to $60 \%(\mathrm{v} / \mathrm{v})$ of $\mathrm{HCl}$. No differences in reduction efficiency of the different Se species were observed when the $\mathrm{KBr}$ concentration was varied. This showed that $\mathrm{KBr}$ was not necessary. Thus, $\mathrm{HCl}$ was sufficient for a quantitative pre-reduction of the different Se species and $60 \%(\mathrm{v} / \mathrm{v}) \mathrm{HCl}$ was used to ensure the efficient and quantitative pre-

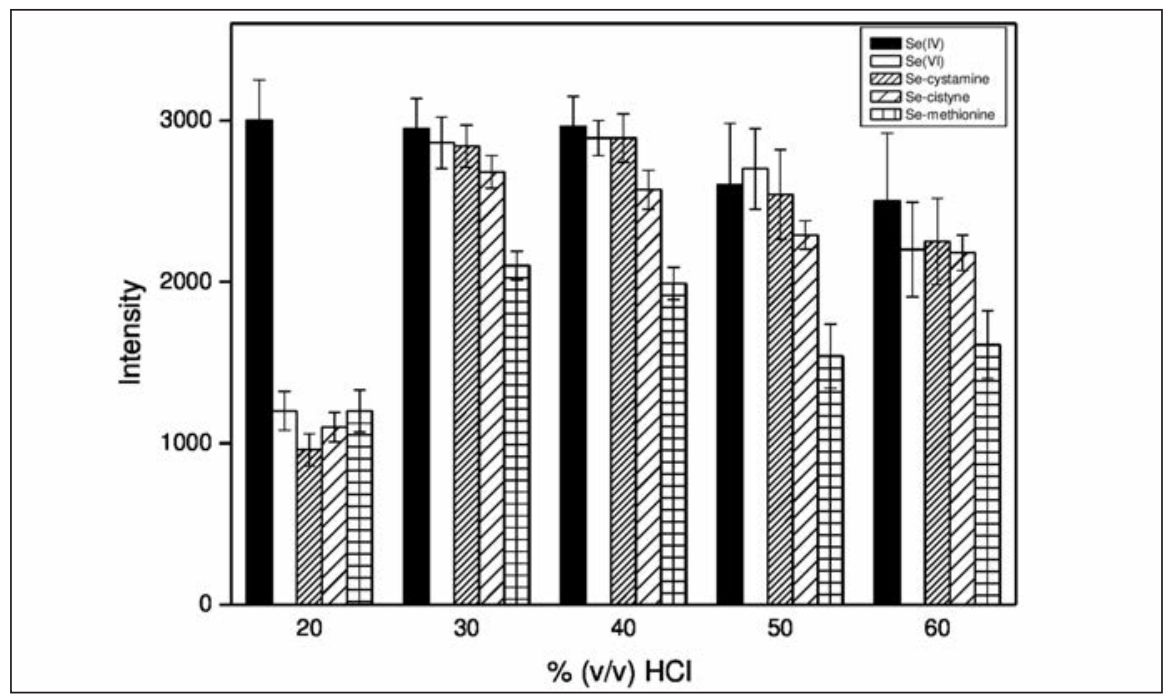

Fig. 2. Pre-reduction step for the different Se species in different $\mathrm{HCl}$ concentrations.

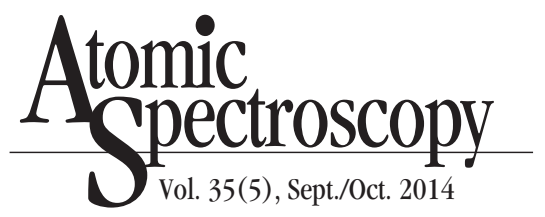

reduction of the different organic and inorganic Se species in blood extract.

\section{Selenium Speciation in Blood}

The type and composition of the mobile phase is another factor that could influence the efficiency of the pre-reduction step and subsequently the HG-ICP-OES detection system. The acetate and phosphate buffers studied at the different $\mathrm{pH}$ values did not show a decrease in the efficiency of the pre-reduction step. However, when the salicylic buffer was tested at the different $\mathrm{pH}$ values, a decrease in the emission intensities was observed, possibly resulting in a negative effect in the process (mainly pre-reduction and generation). Thus, the salicylic buffer was discarded and not further evaluated. In the separation process using the phosphate buffer, no difference was observed among the peaks nor any overlaps or enlargements unlike when the acetate and salicylic buffers were used. The total time of the chromatogram was practically the same, which shows very similar behavior between the speciation in the aqueous standard solution and the degraded bovine blood sample, resulting in good efficiency of the sample preparation step. Concentrations lower than $40 \mathrm{mmol} \mathrm{L}^{-1}$ of phosphate buffer provided overlap peaks of Se-methionine and cysteine; however, Se-cysteine, $\mathrm{Se}(\mathrm{IV})$, and $\mathrm{Se}$ (VI) resulted in three good defined peaks. This mobile phase concentration produced higher retention time. Concentrations higher than $40 \mathrm{mmol} \mathrm{L}^{-1}$ provided overlap peaks for the Se organic and inorganic species and resulted in two peaks.

The mechanism of separation was based on $\mathrm{pK}_{\mathrm{a}}$, the polarity difference. Therefore, the $\mathrm{pH}$ of the solution is a very important factor that influences the separation of the Se species. The $\mathrm{pH}$ range studied was 4 to 8 . A higher retained 
time of the Seleno-amino acids was observed when the $\mathrm{pH}$ values used were above 6 . In the $\mathrm{pH}$ range of 4 to 6 , the $\mathrm{H}_{2} \mathrm{PO}_{4}$ species are predominant in the buffer, while in the 6 to $8 \mathrm{pH}$ range there is equilibrium of two forms, $\mathrm{H}_{2} \mathrm{PO}_{4}{ }^{-}$and $\mathrm{HPO}_{4}{ }^{2-}$ (Figure 3). This difference of the mobile phase species influenced the separation, proposing a stronger interaction of the analyte and the column.

The mobile phase buffer at $\mathrm{pH} 6$ showed stronger interaction between column and $\mathrm{SeO}_{4}{ }^{2-}(\mathrm{SeVI})$ and $\mathrm{HSeO}_{3}{ }^{-}$(SeIV), resulting in slower elution, while the Se organic species eluted faster and resulted in a minor interaction with the column. The run time for speciation of these five Se forms was 16 minutes, which is very good.

The speciation of Se in the samples of bovine blood using the proposed HPLC-UV-HG-ICP-OES system with a $40 \mathrm{mmol} \mathrm{L}^{-1}$ phosphate buffer at pH 6.0 was accomplished with success, and identification of the Se forms was made by injecting each one. After identification and establishing the retention times of each peak, a sample containing $0.5 \mathrm{mg}$ $\mathrm{L}^{-1}$ of each species was injected and speciation of the five peaks was accomplished. In the blood samples, however, identification and quantification of the species of Se was not possible using the proposed method, possibly due to the low selenium content in the blood samples (Figure 4).

\section{Analytical Performance}

Calibration curves with good linear correlation coefficients $(r>0.995)$ were obtained within the 10 to $200 \mu \mathrm{g} \mathrm{L}^{-1}$ Se concentration range in the treated blood samples. The aqueous solution curve should not be used as calibration curve for speciation of Se compounds since the matrix matching mode was found to be more adequate. The relative standard devia- tions $(\mathrm{n}=12)$ were $<8 \%$, the limits of detection 9.5, 7.2, 5.8, 3.1, 4.4 $\mu \mathrm{g} \mathrm{L}^{-1}$, and the limits of quantification were $31.4,23.9,20.1,10.5$, and $14.5 \mu \mathrm{g} \mathrm{L}^{-1}$ for selenocystamine, Se-methylselenocysteine, seleno-DLmethionine, Se(IV), and Se(VI), respectively. The precision was checked by recovery studies and adding $0.50 \mathrm{mg} \mathrm{L}^{-1}$ of each species of selenium to the blood samples. The results in Table II show recoveries within 88 and $96 \%$ for selenocystamine, 86 and $96 \%$ for Semethylselenocysteine, 82 and 90\% for seleno-DL-methionine, 90 and 96\% for Se (IV), 96 and 104\% for $\mathrm{Se}(\mathrm{VI})$.

The lower quantities can be explained by the fact that the blood samples were from cattle without selenium supplements in the feed. Another factor is the dilution of the samples in the chromatographic column of the separation system, where only $100-\mu \mathrm{L}$ samples were injected into the column. However, the addition/recovery studies showed that the developed method showed promising results when the selenium concentrations are in the higher range (Figure 4). In addition, a method is proposed for selenium speciation in blood samples using a hyphenated and alternative ICP-OES system with an $\mathrm{HG}$ technique together with an enzymatic sample preparation step.

\section{CONCLUSION}

An alternative hyphenated technique is described using an on-line pre-reduction HPLC-UV-HG-ICP-OES system for Se speciation in bovine blood. The study confirms that selenium speciation is possible using a buffer phosphate medium. The use of enzymatic extraction solves the big problem of maintaining the composition, chemical structure and information, a challenge for speciation analysis. The proposed detection system for selenium speciation using pre-reduction/hydride generation was accomplished with success in addition to being a very inexpensive technique. The optimized methodology shows good performance for selenium speciation in bovine blood and could be applied to different areas such as nutrition and reproduction.

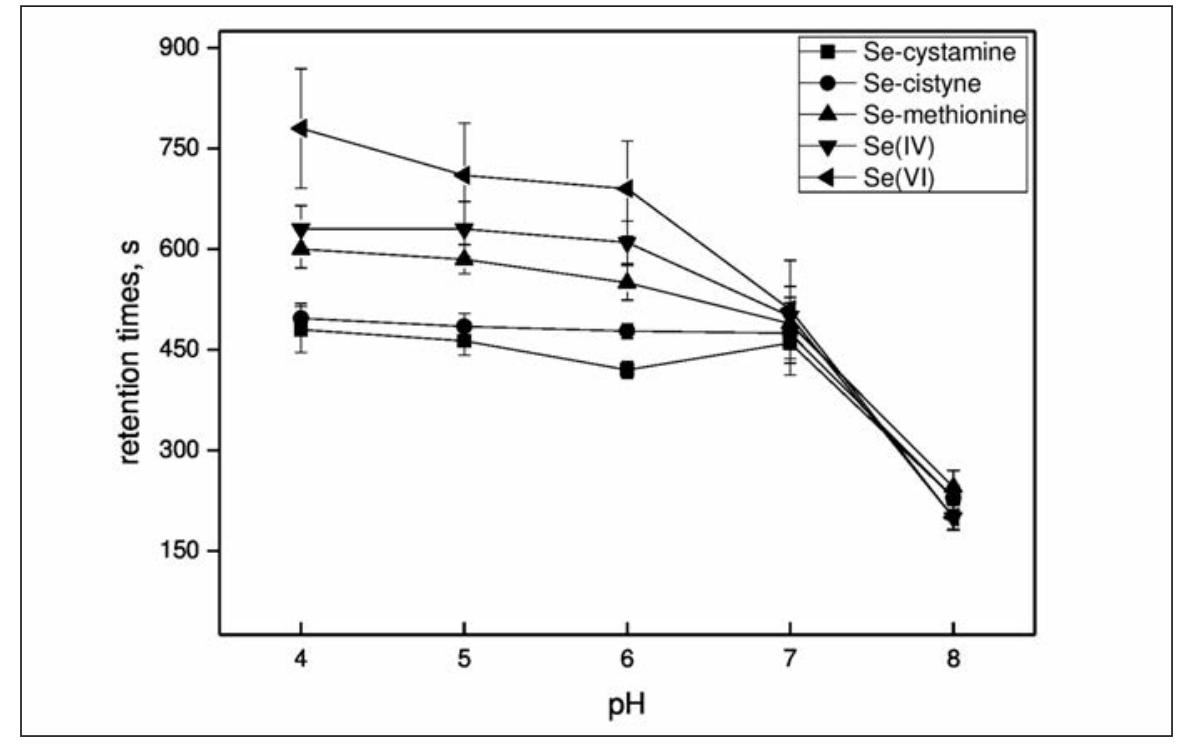

Fig. 3. Influence of buffer mobile phase pH on retention times of Se species. 
TABLE II

Results (medium \pm SD) of (\%)Recovery for Se(IV), Se(VI), Se-cystamine (Se-Cys), Se-cysteine (Se-Cyst), and Se-methionine (Se-Met) From Different Blood Samples

\begin{tabular}{|c|c|c|c|c|}
\hline $\begin{array}{c}\text { Blood } \\
\text { Samples }\end{array}$ & Species & $\begin{array}{l}\text { Spiking } \\
\left(\mathrm{mg} \mathrm{L}^{-1}\right)\end{array}$ & $\begin{array}{r}\text { Recovery } \\
\left(\mathrm{mg} \mathrm{L}^{-1}\right)\end{array}$ & $\begin{array}{c}\text { Recovery } \\
(\%)\end{array}$ \\
\hline \multirow[t]{5}{*}{1} & $\mathrm{Se}(\mathrm{IV})$ & 0.5 & 0.48 & 96.0 \\
\hline & $\mathrm{Se}(\mathrm{VI})$ & 0.5 & 0.51 & 102 \\
\hline & Se-Cys & 0.5 & 0.48 & 96.0 \\
\hline & Se-Cyst & 0.5 & 0.47 & 94.0 \\
\hline & Se-Met & 0.5 & 0.45 & 90.0 \\
\hline \multirow[t]{5}{*}{2} & $\mathrm{Se}(\mathrm{IV})$ & 0.5 & 0.47 & 94.0 \\
\hline & $\operatorname{Se}(V I)$ & 0.5 & 0.49 & 98.0 \\
\hline & Se-Cys & 0.5 & 0.46 & 92.0 \\
\hline & Se-Cyst & 0.5 & 0.46 & 92.0 \\
\hline & Se-Met & 0.5 & 0.44 & 88.0 \\
\hline \multirow[t]{5}{*}{3} & $\mathrm{Se}(\mathrm{IV})$ & 0.5 & 0.47 & 94.0 \\
\hline & $\mathrm{Se}(\mathrm{VI})$ & 0.5 & 0.52 & 104 \\
\hline & Se-Cys & 0.5 & 0.46 & 92.0 \\
\hline & Se-Cyst & 0.5 & 0.48 & 96.0 \\
\hline & Se-Met & 0.5 & 0.42 & 84.0 \\
\hline \multirow[t]{5}{*}{4} & $\mathrm{Se}(\mathrm{IV})$ & 0.5 & 0.45 & 90.0 \\
\hline & $\mathrm{Se}(\mathrm{VI})$ & 0.5 & 0.48 & 96.0 \\
\hline & Se-Cys & 0.5 & 0.43 & 86.0 \\
\hline & Se-Cyst & 0.5 & 0.44 & 88.0 \\
\hline & Se-Met & 0.5 & 0.41 & 82.0 \\
\hline
\end{tabular}

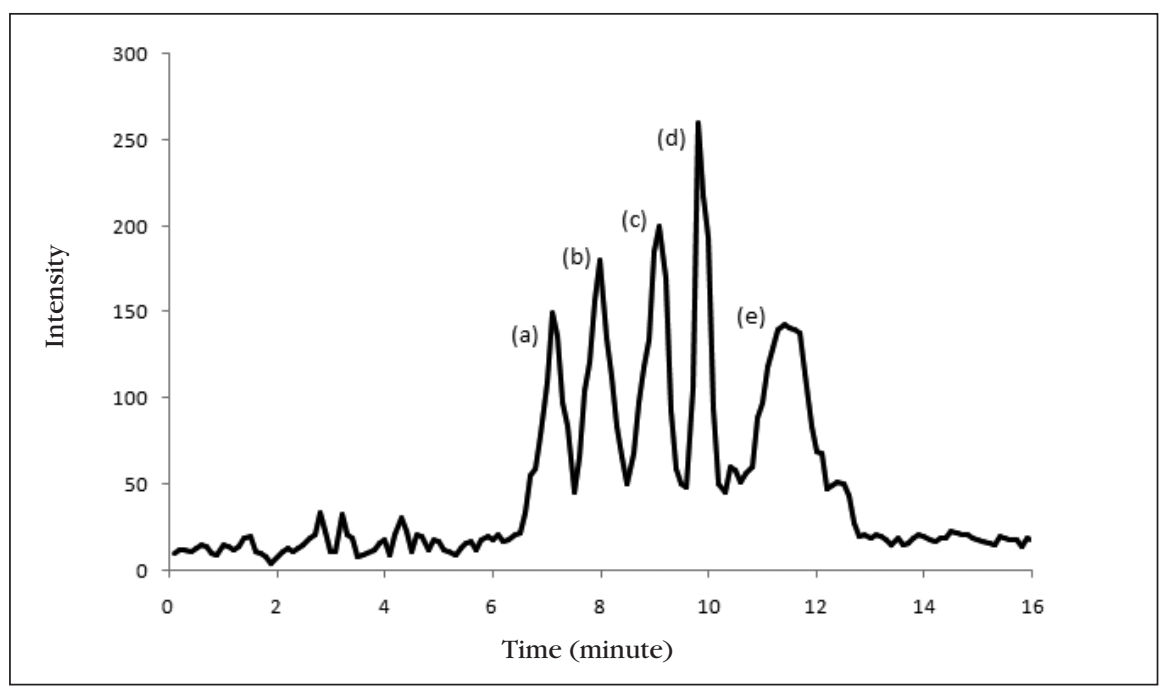

Fig. 4. Chromatogram of the different species of Se in bovine blood after enzymatic bydrolysis using phosphate buffer of $40 \mathrm{mmol} \mathrm{L}^{-1}$ at $\mathrm{pH}=6$ and columns of anionic exchange. (a) Seleno-cystamine, (b) Seleno-cysteine, (c) Seleno-methionine, (d) $\mathrm{Se}(\mathrm{IV})$, and (e) $\mathrm{Se}(\mathrm{VI})$.

\section{Atomic Spectroscopy \\ 1 Vol. 35(5), Sept./Oct. 2014}

\section{ACKNOWLEDGMENT}

The authors thank the Fundação de Amparo à Pesquisa do Estado de São Paulo and Conselho Nacional de Desenvolvimento Científico e Tecnológico for financial support of this work and for fellowships to G.P.G.F. and A.R.A.N.

Received May 21, 2014. 


\section{REFERENCES}

1. G. Ballihaut, L.E. Kilpatrick, E.L. Kilpatrick, and W.C. Davis, Metallomics 4, 533 (2012).

2. K. Suzuki, J. Health Science 51, 107 (2005).

3. R. Lobinski and M.Potin-Gautier, Analusis Magazine 26, M21 (1998).

4. W. Shiand, M.R. Chance, Cel. Molec. Life Sci. 65, 3040 (2008).

5. N. Jakubowski, R.Lobinski, and L. Moens, J. Anal. At. Spectrom. 19, 1 (2004).

6. Y. Ogra, T. Kitaguchi, K. Ishiwata, N. Suzuki, T. Toida, and K. T. Suzuki, Metallomics 1, 78 (2009).

7. L.A. Ba, M. Doering, T. Burkholz, and C. Jacob, Metallomics 1, 292 (2009).

8. L. Ling, S. Mo, P. Zhang, Y. Cai, S. Mou, G. Jiang, and M. Wen, J. Chromatogr. A 118, 139 (2006).

9. K.M. Brennan, W.R. Burris, J.A. Boling, and J.C. Matthews, Biol. Trace Elem. Res.144, 504 (2011).

10. X. Sum, C.N. Tsang, and H. Sum, Metallomics 1, 25 (2009).

11. D. Pröfrock and A. Prange, Appl. Spectrosc. 66, 843 (2012).

12. Y. Arslan, E. Yildirim, M. Gholami, and S. Bakirdere, Trends in Anal. Chem. 30, 569 (2011).

13. C.F. Harrington, R. Clough, H.R. Hansen, S. J. Hill, S. A. Pergantise, and J. F. Tyson, J. Anal. At. Spectrom. 24, 999 (2009).

14. D. Sanchez-Rodas, W.T. Corns, B. Chenb, and P.B. Stockwell, J. Anal. At. Spectrom. 25, 933 (2010).

15. P. Pohland and P. Jamroz, J. Anal. At. Spectrom. 26, 1317 (2011).

16. J.L. Capelo, C. Fernandez, B. Pedras, P. Santos, Pablo Gonzalez, and C. Vazb, Talanta 68, 1442 (2006).

17. J. Dai, F. L. Ren, C.Y. Tao, and Y. Bai, Int. J. Mol. Sci. 12, 4009 (2011).

18. F. Hellaland and M. Dachraoui, Talanta 63, 1089 (2004).
19. L. Kozak, M. Rudnicka, and P. Niedzielski, Food Anal. Methods 5, 1237 (2012).

20. M. Gallignani, M. Valero, M.R. Brunetto, J.L. Burguera, M. Burguera, and Y.P. Peña, Talanta 52, 1015 (2000).

21. D. Sanchez-Rodas, F. Mellano, E. Morales, and I. Giraldez, Talanta 106, 298 (2013).

22. H. Li, Y. Luo, Z. Li, L. Yang, and Q. Wang, Anal. Chem. 84, 2974 (2012).

23. Y.W. Chena and N. Belzile, Anal. Chim. Acta 671, 9 (2010).

24. O. Cremades, M. M. Diaz-Herrero, P. Carbonero-Aguilar, J.F. GutierrezGil, E. Fontiveros, B. RodríguezMorgado, J. Parrado, and J. Bautista, Food Chem.133, 1538 (2012).

25. A.I. Cabañero, Y. Madrid, and C. Cámara, Anal. Bioanal. Chem. 381, 373 (2005).

26. L. H. Reyes, J. L. G. Mar, G.M. M. Rahman, B. Seybert, T. Fahrenholz, and H.M.S. Kingston, Talanta 78, 983 (2009).

27. V. Gergely, K.M. Kubachka, S. Mounicou, P. Fodor, and J.A. Caruso, J. Chromatogr. A 1101, 94 (2006).

28. C.C. Crispino, S.G. Lemos, M.Y. Kamogawa, and A.R.A. Nogueira, Braz. J. Anal. Chem. 10, 460 (2013). 